\title{
Professor supervisor do Pibid: ser docente com capa de gestor
}

Laura Noemi Chaluh ${ }^{1}$

\section{Resumo}

O presente trabalho é um recorte de uma pesquisa qualitativa de orientação sócio-histórica que objetivou analisar e compreender os processos formativos promovidos por duas professoras supervisoras que participaram do subprojeto Pibid (Programa Institucional de Bolsas de Iniciação à Docência) vinculado ao Curso de Pedagogia, de uma universidade pública do Estado de São Paulo e que foi desenvolvido em uma Escola Municipal de Ensino Fundamental. Para compor o trabalho socializo uma escrita produzida por uma das professoras supervisoras. As análises identificam o lugar da professora supervisora como coformadora dos futuros professores atribuindo também capacidade na gestão.

Palavras-chave: Pibid; Professor Supervisor; Formação; Gestão.

\section{Profesor supervisor del Pibid: ser docente con capa de gestor}

\section{Resumen}

El presente trabajo es un recorte de una investigación cualitativa de orientación socio-histórica que tuvo como objetivo analizar y comprender los procesos formativos propuestos por dos profesoras supervisoras que participaron del sub proyecto Pibid (Programa Institucional de Iniciación a la Docencia) vinculado al Curso de Pedagogía, de una universidad pública do Estado de São Paulo y que fue desarrollado en una Escuela Municipal de Enseñanza Primaria. Para la composición del trabajo socializo una escrita producida por una de las profesoras supervisoras. Los análisis identifican el lugar de profesora supervisora como coformadora de futuros profesores atribuyendo también capacidad para la gestión.

Palabras clave: Pibid; Profesor Supervisor; Formación; Gestión.

\section{Introdução}

Fui responsável por coordenar o Subprojeto de Pedagogia do Programa Institucional de Bolsas de Iniciação à Docência de uma universidade estadual do interior do estado de São Paulo e que foi desenvolvido em uma Escola Municipal que oferece os Anos Iniciais do Ensino Fundamental. O subprojeto foi definido junto com a equipe da escola ao ver a necessidade conjunta de organizar o trabalho pedagógico, tendo como foco o incentivo às práticas de leitura. A proposta de trabalho teve a intencionalidade de contribuir na promoção de sujeitos leitores, tanto os alunos da escola, quanto o coletivo de professores, a partir de projetos interdisciplinares que considerassem a literatura como pauta para a formação de leitores. Articulando o Projeto

\footnotetext{
${ }^{1}$ Universidade Estadual Paulista, UNESP. Rio Claro. Endereço Eletrônico: laura.chaluh@unesp.br Periódico Horizontes - USF - Itatiba, SP-Brasil - e019003
} 
Político Pedagógico da escola com o subprojeto Pibid, definimos que o eixo central do trabalho era a busca por "formar leitores, possibilitando a vivência de emoções, o exercício da fantasia e da imaginação", que conseguissem "dominar instrumentos básicos da cultura letrada, compreendendo os diferentes tipos de textos que permitam aos educandos compreender e atuar no mundo em que vivem" (ESCOLA DANTE EGRÉGGIO, 2011, p. 22-25).

Do subprojeto participaram 10 bolsistas de iniciação à docência (ID) do curso de Licenciatura Plena em Pedagogia da referida universidade, duas professoras supervisoras da escola (orientaram e viabilizavam as atividades das bolsistas na escola), uma professora colaboradora/orientadora (participou do subprojeto e orientou bolsistas) da universidade e eu, como responsável pela coordenação do subprojeto e orientadora.

O Programa Institucional de Bolsas de Iniciação à Docência (Pibid) foi proposto, em 2007, pelo MEC/Capes (Ministério da Educação/Coordenação de Aperfeiçoamento de Pessoal de Nível Superior). Dentre os objetivos do Programa é relevante a ideia de elevar a qualidade da formação inicial de professores nos cursos de licenciatura ao promover a integração entre Ensino Superior e Educação Básica. Merece destaque para os fins deste trabalho o objetivo que explicita a possibilidade de mobilizar professores das escolas públicas para que ocupem o lugar de coformadores dos futuros docentes, assumindo o protagonismo pelos processos de formação inicial, o que foi feito pelas duas professoras supervisoras envolvidas no nosso subprojeto.

Para o desenvolvimento do subprojeto, foram instituídos espaços de formação coletivos para dar suporte aos bolsistas. Isto porque eles se inseriam no cotidiano da escola, semanalmente, e desenvolviam projetos de literatura em parceria com a professora que acompanhavam $^{2}$ (professoras colaboradoras). Um desses espaços, na escola, com reuniões quinzenais, era realizado sob responsabilidade das professoras supervisoras e objetivavam socializar experiências, desenvolver e sistematizar a organização do trabalho pedagógico e de materiais didáticos. Os encontros na universidade, também quinzenais, sob minha

\footnotetext{
${ }^{2} \mathrm{Na}$ escola eram 10 professoras que atendiam 10 turmas, entre o período da manhã e da tarde. Todas receberam bolsistas e são chamadas aqui de professoras colaboradoras. Dentre elas, duas tornaram-se professoras supervisoras do Pibid.
}

Periódico Horizontes - USF - Itatiba, SP-Brasil - e019003 
responsabilidade e da professora colaboradora da universidade, possibilitavam aprofundamento de questões teóricas para sustentar as propostas que as bolsistas desenvolviam em parceria com as professoras das salas de aula, além de socializar experiências e discutir problemáticas vinculadas à educação. Além disso, fiquei responsável por manter encontros individuais com as bolsistas e também mantive encontros com as duas professoras supervisoras para encaminhamentos de trabalho junto às bolsistas e à escola como um todo.

O referido subprojeto Pibid/Pedagogia ganhou outro patamar quando decidi considerálo objeto de estudo de uma pesquisa ${ }^{3}$ sobre as práticas formativas instituídas pelas professoras supervisoras junto com as bolsistas. As questões que nortearam a pesquisa foram: de que forma as professoras supervisoras podem contribuir com a formação inicial das bolsistas do Pibid? Quais os saberes da profissão docente que as professoras supervisoras podem socializar com as bolsistas de Iniciação à docência e que contribuem na constituição docente das mesmas? Quais práticas das professoras supervisoras promovem a formação das bolsistas no contexto escolar? Assumi a pesquisa de orientação sócio-histórica que acredita que, tanto os participantes da pesquisa como os pesquisadores, no encontro, ressignificam-se, aprendendo juntos (FREITAS, 2003). A produção dos dados (escritas produzidas pelas professoras supervisoras e pelas bolsistas) foi analisada a partir do paradigma indiciário (GINZBURG, 1989). Neste trabalho trago elementos para pensar acerca do lugar ocupado por professores supervisores do Pibid.

\section{Produções acerca da temática do professor supervisor}

André (2012) fez uma pesquisa sobre as políticas docentes no Brasil, constituída por 15 estudos de casos em cinco regiões do país. Segundo consta no artigo, um relatório publicado pela Organização de Cooperação e Desenvolvimento Econômico-OCDE (2006), e referente a vários países, sinaliza que as taxas de evasão do magistério são mais altas nos primeiros anos de atividade profissional. Nesse sentido, para reverter a situação, André (2012) considera a

\footnotetext{
${ }^{3}$ Trabalho vinculado à pesquisa "O professor supervisor do Pibid: formador de futuros professores" que recebeu auxílio da FAPESP (№ 2015/18971-8).
}

Periódico Horizontes - USF - Itatiba, SP-Brasil - e019003 
necessidade de políticas e/ou programas de capacitação que ofereçam suporte e acompanhamento aos professores iniciantes. Da pesquisa desenvolvida pela autora interessa, para este trabalho, o levantamento de três programas que buscam uma aproximação entre universidade e escola para a inserção dos futuros professores no contexto escolar de modo a favorecer, também, a inserção na docência: a) o Pibid, em âmbito federal; b) o Bolsa Alfabetização, pelo Estado de São Paulo; c) o Bolsa Estagiário, pelo município de Jundiaí (SP). Entre os programas que estabelecem uma parceria entre a universidade e a escola, com a intenção de oferecer melhor preparo aos futuros docentes, favorecendo sua inserção no magistério, a autora ressalta o Pibid. Segundo André (2012), as avaliações pontuais feitas em relação ao Programa têm evidenciado resultados positivos, destacando entre eles a motivação dos bolsistas para ingressar na profissão e os desafios para os professores das escolas, ao reverem suas práticas em colaboração com os bolsistas.

$\mathrm{Na}$ busca por melhor compreender o lugar ocupado pelos professores supervisores vinculados ao Pibid, fiz levantamento de artigos nos Anais do Congresso Nacional de Educação (EDUCERE), nos anos de 2011, 2013 e 2015. Para a escolha dos artigos foi definida a presença da palavra-chave Pibid no título. Foram encontrados cinco artigos, apresentados na sessão de Comunicação do referido evento, que guardavam relação com o foco da pesquisa em questão: Jardilino, Oliveri (2013); Matsuoka, Signorelli e André (2013); Gaspar (2015); Demos e Terrazzan (2015) e França (2015).

Matsuoka, Signorelli e André (2013) apresentam uma discussão a partir da Portaria 260/2010 que regulamenta o Pibid. Especificamente, argumentam sobre as definições que tratam dos professores das escolas públicas estaduais, municipais ou do Distrito Federal que participam do projeto institucional, designados para supervisionar as atividades dos bolsistas de iniciação à docência. Após análise da referida Portaria, os autores explicitam que, na documentação, são definidas orientações que tratam de ações de ordem organizacional e que nada é sinalizado em relação à sua ação na ordem da formação de futuros professores, das competências docentes necessárias para ocupar esse lugar justificando assim que "o que subjaz ao termo 'co-formador' não se encontra no documento de maneira explícita" (MATSUOKA;

Periódico Horizontes - USF - Itatiba, SP-Brasil - e019003 
SIGNORELLI; ANDRÉ, 2013, p. 8190).

A partir disso, os autores fazem uma série de perguntas no sentido de querer responder o que seria ser um coformador dentro do contexto do Programa e, ainda, como é que se adquirem as competências para poder ocupar esse lugar. Em função disso, consideram que

[...] ao supervisor ainda resta a complexidade de uma tarefa que requer conhecimentos pouco traduzidos para o campo cognitivo, permanecendo dependente do subjetivo, ou melhor, trabalhar na incerteza, ao que parece, guiado pelos elementos surpresa, são características da função do supervisor que atua no acompanhamento das atividades dos bolsistas de iniciação à docência. [...] O que se torna importante para o supervisor nesse contexto? Provavelmente, o que os estudos evidenciam acerca da satisfação profissional dos professores, ou seja, que se concentra na preocupação dos professores em conseguir cumprir sua tarefa de ensinar e o sucesso dos alunos ao aprender (MARCELO, 2010, p.17). Talvez seja essa a base teórico-prática para o supervisor em seu trabalho de orientação aos alunos bolsistas (MATSUOKA; SIGNORELLI; ANDRÉ, 2013, p.8191).

Demos e Terrazan (2015) explicitam que a pesquisa desenvolvida objetivou ampliar a compreensão do lugar ocupado pelo professor supervisor ${ }^{4}$ dos subprojetos Pibid a partir das análises dos Editais e Portarias disponíveis no website do Programa entre os anos de 2007 e 2014. A análise das informações resultantes dos estudos daqueles documentos possibilitou afirmar que há avanços em relação ao reconhecimento e importância do papel do professor supervisor do Pibid, como profissional.

A seguir destaco algumas das considerações elencadas pelos autores após análises dos referidos documentos. Há uma evolução em termos de desenvolvimento nos Editais e Portarias analisados acerca da importância profissional do professor supervisor, enquanto principal mediador entre as escolas e os Institutos de Ensino Superior e, também, enquanto um dos agentes principais na execução e cumprimento disto, na escola, o que possibilita um desenvolvimento profissional por meio da troca de conhecimentos acadêmicos e escolares com os bolsistas de iniciação à docência. Também os autores perceberam uma valorização da escola

\footnotetext{
${ }^{4}$ Os autores, ao longo do artigo, referem-se ao Bolsista Supervisor (BS) ao tratar do que neste artigo focamos como professor supervisor.
}

Periódico Horizontes - USF - Itatiba, SP-Brasil - e019003 
como lócus de formação docente.

Demos e Terrazan (2015) explicitam que é no ano de 2009 que aparece nos documentos oficiais, o termo coformação e o reconhecimento do professor supervisor enquanto profissional. Ainda, os autores afirmam que, em 2013, aparecem indícios de que o processo de inserção à docência e a possibilidade de apropriação e reflexão dos saberes vinculados à docência pelos bolsistas de iniciação à docência também são mediados pelos professores supervisores. Os autores ainda explicitam que no Edital de 2009, as tarefas dos professores supervisores eram de caráter administrativo e de supervisão. Porém, os autores sinalizam que, a partir da Portaria no 260, de 30 de dezembro de 2010, é que é perceptível uma atenção para tarefas próprias de coformação profissional docente.

A seguir, apresento os quatro artigos que socializam pesquisas com professores supervisores do Pibid.

Jardilino e Olivieri (2013) discutem o impacto do Pibid na formação continuada dos professores supervisores das escolas e ainda investigam quais os motivos que os levaram a participar do programa, as dificuldades que enfrentaram e os espaços culturais e formativos que foram proporcionados pelo fato de fazer parte do Programa, assim como dizem do impacto do Pibid na escola. Desenvolveram a pesquisa na Região dos Inconfidentes, em Minas Gerais, e com professores supervisores que estavam vinculados ao Pibid do curso de Pedagogia da Universidade Federal de Ouro Preto. Segundo os autores, o Pibid,

[...] Esse programa também contribui para a promoção da formação continuada, pois abre espaço para que essa ocorra através dos momentos de troca de experiências entre professores supervisores, coordenadores e alunos da formação inicial, reflexão sobre a própria prática; reflexão e discussão sobre o estudo da teoria e sua aplicação na sala de aula. [...] Os docentes reconhecem o programa como um espaço de promoção da formação continuada pelo fato de contribuir para a melhoria da sua prática e para a formação dos futuros professores, pois os ajudam a adquirir novos conhecimentos (JARDILINO; OLIVIERI, 2013, p.7847).

Matsuoka, Signorelli, André (2013) socializam resultados de pesquisa que estudou a

Periódico Horizontes - USF - Itatiba, SP-Brasil - e019003 
integração universidade-escola possibilitada pelo Pibid e que contava com a atuação de uma professora supervisora no subprojeto de Educação Infantil do curso de Pedagogia da Universidade Federal de Uberlândia (UFU), campus de Ituiutaba/MG. A professora supervisora tinha seis alunas bolsistas sob sua orientação. Duas destas bolsistas desenvolviam atividades na sala de aula onde a própria supervisora era a professora regente. As pesquisadoras argumentam que a integração universidade-escola é possível por ter configurado um espaço de interlocução que promoveu a constituição dos sujeitos. Para os autores, a supervisora foi uma intermediadora entre a instituição formadora e atuou "como coformadora ao criar situações didáticas mediatizadoras, capazes de desenvolver nas alunas bolsistas competências e habilidades relevantes para o processo de formação da docência". Concluem que a escola básica "atua como catalisadora de movimentos impulsionadores do processo de formação continuada de seus pares" (MATSUOKA, SIGNORELLI, ANDRÉ, 2013, p.8187).

Gaspar (2015) socializa uma pesquisa realizada no âmbito do Pibid, no Instituto Federal do Triângulo Mineiro (IFTM). Interessa para este trabalho os questionários respondidos por 19 professores supervisores, a partir dos quais foi possível identificar quais as contribuições advindas da prática da supervisão. Segundo Gaspar (2015), os resultados possibilitaram compreender que o Programa traz contribuições tanto para a formação inicial como continuada dos professores da Educação Básica. Em relação aos resultados da pesquisa, o autor argumenta que

\begin{abstract}
A pesquisa registrou que o papel do professor supervisor é relevante e essencial na formação do licenciando, na medida em que esse profissional, por ser detentor de saberes experienciais e específicos, influencia diretamente na concepção do trabalho docente. A pesquisa revelou também que existe um forte envolvimento do professor supervisor com o aluno bolsista em todas as etapas: planejamento, acompanhamento e avaliação das atividades pedagógicas propostas nos subprojetos. [...] Averiguamos que os professores da educação básica dedicam-se bastante para tornar a supervisão de fato colaborativa e producente. É bem marcada a atuação dos professores supervisores no auxílio aos alunos bolsistas para preparação de material didático e de apoio à prática docente (GASPAR, 2015, p.6201).
\end{abstract}

Segundo Gaspar (2015), a percepção dos participantes da pesquisa é a de que o Pibid

Periódico Horizontes - USF - Itatiba, SP-Brasil - e019003 
efetivamente é um programa que promove a troca de conhecimentos e vivências e que pode contribuir para a elevação da referência identitária que os futuros docentes podem vir a constituir.

França (2015) socializa resultados de uma pesquisa da qual participaram oito professoras supervisoras do Pibid da Universidade Estadual do Ceará (UECE), integrantes do Subprojeto do curso de Pedagogia da Faculdade de Educação de Crateús (FAEC). Foram utilizados questionários e a segunda parte do mesmo era composta por 8 questões mistas que objetivavam conhecer as opiniões das professoras supervisoras sobre o trabalho formativo que desenvolviam no Subprojeto do Pibid. Segundo França (2015, p. 4149), “a ideia era perceber se elas conseguiriam reconhecer algum movimento de autoformação no processo que desenvolviam na escola visando o fortalecimento da formação dos licenciandos". Os resultados da pesquisa indicam que as professoras supervisoras reconhecem que as experiências vivenciadas no contexto do Pibid "podem ressiginificar suas práticas pelo exercício da pesquisa em sala de aula possibilitada pelas atividades de observação e, ainda, pela vivência das práticas educativas nas escolas" (FRANÇA, 2015, p. 4149), sendo que as professoras supervisoras "destacam o saber de experiência como fundamental à formação permanente em que se encontram no projeto" (FRANÇA, 2015, p. 4149). Ainda foi solicitado que elas citassem três habilidades relacionadas à prática docente que acreditavam que tinham sido aperfeiçoadas após o ingresso no Pibid Pedagogia. França (2015, p. 4152) destaca dentre as respostas dadas dois aspectos principais:

[...] relacionais (modo de falar, modo de ouvir os alunos, entendimento da realidade dos alunos, espírito de liderança, trabalho em grupos); e pedagógicos (planejamento das atividades e das avaliações de aprendizagem, preparação de material didático para as aulas, pesquisa de conteúdos para aprofundar os conhecimentos, observação do desenvolvimento das habilidades de leitura e de escrita dos alunos, percepção das individualidades dos alunos, melhoria das técnicas de contar e de ler histórias para as crianças, dentre outras).

Os artigos acima citados apresentam, então, as implicações do Pibid na constituição das professoras supervisoras e o destaque do lugar que ocupam no contexto do referido Programa contribuindo na formação de futuros professores.

Periódico Horizontes - USF - Itatiba, SP-Brasil - e019003 


\section{Das práticas da professora supervisora Bétsamar}

Apresento um recorte de alguns dados produzidos no projeto de pesquisa aqui socializado. Como já explicitado, o mesmo tem como sujeitos de pesquisa as duas professoras supervisoras que participam do subprojeto referido anteriormente. Porém, neste trabalho, apenas apresento a escrita produzida pela professora supervisora Bétsamar.

Na pesquisa desenvolvida por Gatti et al. (2014), explicita-se de que forma o Pibid tem contribuído com os professores supervisores da escola: contribui com a formação continuada dos docentes das escolas e estimula a busca de novos conhecimentos dando continuidade aos estudos; o professor supervisor, ao estar vinculado ao meio acadêmico, tem a possibilidade de articular o conhecimento acadêmico com o conhecimento da prática em uma perspectiva formativa; possibilita a reflexão sobre a prática com apoio dos bolsistas e professores das instituições de Ensino Superior em ações compartilhadas, aumenta a motivação do docente ao ter maior envolvimento em atividades diversificadas; potencializa mudanças em perspectivas profissionais e aprendizagens e contribui para a melhoria de seu desempenho; valoriza e reconhece o professor e seu trabalho na escola.

Os dados da pesquisa de Gatti et al. (2014) explicitam de que forma o trabalho desenvolvido a partir do Pibid promove a formação dos professores supervisores. Na pesquisa desenvolvida por mim, pretendi olhar para as práticas de formação instituídas pelas professoras supervisoras junto com as bolsistas de iniciação à docência, para entender como elas se constituem também formadoras das bolsistas no contexto escolar.

Como parte da avaliação do trabalho desenvolvido pelas professoras supervisoras no final do ano de 2016, solicitei que elas produzissem uma carta que tivesse como destinatário imaginário um "professor supervisor novato". Socializo aqui fragmentos da carta produzida por Bétsamar", que, ao apresentar seu trabalho para um "novato", diz de algumas práticas que considera fixas, pela sua relevância,

\footnotetext{
${ }^{5} \mathrm{~A}$ professora supervisora autorizou a utilização do seu nome verdadeiro. Agradeço à professora pela autorização. Periódico Horizontes - USF - Itatiba, SP-Brasil - e019003
} 
[...] Práticas que proponho (e vivencio) como fixas:

$\checkmark$ Leituras fruitivas, levadas por você ou pelos bolsistas. Estas leituras podem servir como sugestões para trabalhos parceiros ou simplesmente ser um momento de descontração no grupo.

$\checkmark$ Registros: todas as reuniões têm um registro. Para não sobrecarregar ninguém, ele é feito em rodízio. Inicialmente os registros são enviados a mim e a minha parceira supervisora, depois de nossas contribuições é socializado com todos. Os registros são importantes para documentar "nossa história", possibilitando consultas posteriores, podendo tirar dúvidas, auxiliar em regaste de ideias a serem usadas nas práticas parceiras ou futuras.

$\checkmark$ Socialização de atividades: bolsistas são incentivados a trazerem para as nossas reuniões atividades parceiras desenvolvidas, expor materiais construídos etc, dando aos colegas oportunidades de ideias para trabalhos futuros, seja nas parcerias, seja quando estiverem exercendo a docência.

$\checkmark$ Partilhar: momento em que todos os bolsitas falam de suas práticas parceiras, para expor dúvidas, expectativas, alegrias, frustrações... Muitas vezes, a partir do que fala, o bolsista ouve palavras de apoio, sugestões etc... [...] (Carta de Bétsamar, dezembro de 2016).

Destaco a importância das leituras fruitivas, uma vez que o nosso projeto tinha como eixo a literatura no contexto escolar e, nesse sentido, era fundamental que os bolsistas experienciassem essa prática nos encontros com as professoras supervisoras. Porém, a prática da escrita, a socialização de experiências e o partilhar de dúvidas e anseios considero que merecem ênfase enquanto proposta formativa. Bétsamar destaca a "importância de socializar e partilhar da/e sobre sua prática, pensando coletivamente. Invista no valor que muitos trabalhos docentes têm e que muitas vezes ficam "presos" dentro da sala de aula...".

Por outro lado, para além dessas práticas chamadas por Bétsamar como fixas, ela chama a atenção para outras que, segundo ela, são relevantes e tem a ver com: organização do trabalho; prazos e horários; e importância do planejamento e da documentação pedagógica, seja com fotos e/ou registros pessoais. Para ela, as questões mais pessoais têm a ver com a postura perante a classe e a forma com que se relacionam/observam as professoras colaboradoras, aquelas que abrem as portas da sala de aula para poder desenvolver a proposta do subprojeto Pibid.

Outras práticas, nem sempre fixas, mas de igual relevância, conforme a ocasião solicita, referem-se a auxiliar os bolsistas no hábito da organização do trabalho docente, incentivando-os a cumprirem prazos e horários, investir em bons

Periódico Horizontes - USF - Itatiba, SP-Brasil - e019003 
planejamentos, em fotos de atividades, em registros pessoais. Converse com os bolsistas sobre posturas adequadas em classe, tanto no desenvolver dos trabalhos parceiros quanto ao observar/aprender a partir do exercer docente de seus professores colaboradores. (Carta de Bétsamar, dezembro de 2016)

Por outro lado, Bétsamar afirma a importância de auxiliar os bolsistas a estarem atentos "à dinâmica escolar, informando-os de recados/decisões da gestão, sempre que estes, de alguma forma, tiverem ligação com o trabalho parceiro e/ou com a presença deles na escola" (Carta de Bétsamar, dezembro de 2016). Isto porque Bétsamar sinaliza que, como professora supervisora, é uma ponte entre bolsistas e gestão. Também sinaliza a necessidade de que, quando os bolsistas têm inquietações que ela não pode resolver, solicita ajuda à equipe de gestão, para que consiga auxiliá-los com suas interrogações.

E o que se aprende estando no lugar de professora supervisora? Bétsamar afirma que se aprende com os bolsistas, pois "Eles, no frescor de sua formação inicial, vêm com muitas ideias, dúvidas, sugestões e, cada uma delas, são oportunidades para você repensar sua prática, repensar seu lugar na escola, repensar seu lugar de professor supervisor..." (Carta de Bétsamar, dezembro de 2016). Também Bétsamar dá um destaque ao aprender dos professores colaboradores, aqueles que recebem bolsistas Pibid. Acredito que isso seja um diferencial legitimado pela professora supervisora, porque ainda que seja difícil de contornar, definitivamente tem sido uma possibilidade efetiva para conhecer mais dos seus colegas.

Você não vai lidar apenas com os bolsistas, também irá lidar com os professores que os recebem. Esta situação poderá aproximá-la mais daqueles que já são seus companheiros de docência. Com esta proximidade, aprenderá mais da prática de cada um deles, aprenderá sobre como atendem alguém semanalmente presente em sua sala, aprenderá sobre como ajudar este que se disponibilizou a ajudar na formação de um bolsista. Nesta relação, você estará em contato com um companheiro docente seu, isto, nem sempre é fácil, sendo assim, não hesite em pedir ajuda, para sua Coordenadora do Pibid, para a Professora Coordenadora de sua escola. Lembre-se, contar com o apoio de outros, sempre é muito bom! (Carta de Bétsamar, dezembro de 2016).

Outro ponto que aparece na carta é que o professor supervisor é um colaborador:

Periódico Horizontes - USF - Itatiba, SP-Brasil - e019003 
[...] Colaborador, principalmente na formação do aluno bolsista, mas também colaborador no processo ensino aprendizagem dos alunos da escola, colaborador nas pontes necessárias para que o trabalho aconteça de forma prazerosa, mas também comprometida. Lembre-se, seja também "colaboradora" de sua aprendizagem/formação! Contar com quem aprender sempre é válido e enriquece seus recursos a serem investidos em prol do outro, aluno bolsista, companheiros de trabalho, alunos da escola... Aqui, enfatizo o apoio que sempre tive das Coordenadoras do Pibid na universidade. Elas, antes de serem "da chefia", sempre foram algumas de minhas maiores "professoras" em todo o processo de ser/estar supervisora Pibid (Carta de Bétsamar, dezembro de 2016).

Bétsamar explicita a potencialidade de "ser/estar professora supervisora". Um lugar que, ocupado com compromisso, não apenas atinge a constituição docente das bolsistas, futuras professoras, mas também tem implicações nos processos de aprendizagem dos alunos da escola, na constituição docente das professoras colaboradoras e na formação das próprias professoras supervisoras. Gatti et al. (2014) legitimam os dizeres da professora supervisora Bétsamar. Segundo os autores, o Pibid contribui com a formação continuada qualificada dos docentes das escolas; aproxima o professor supervisor do meio acadêmico; possibilita a reflexão e o questionamento sobre a prática em diálogo com os bolsistas e os professores da universidade; aumenta a motivação do docente pelo seu maior envolvimento em atividades diversificadas; e propicia mudanças nas perspectivas profissionais.

Ser professor supervisor no contexto de nosso subprojeto Pibid implica assumir o compromisso e a responsabilidade pela formação dos bolsistas, tendo, como pano de fundo, a ideia de super-visão. Ideia que surgiu em conversas com o grupo e que vai contra o conceito de supervisão como controle/vigilância. Eu tenho explicitado que as professoras supervisoras têm construído uma super-visão no sentido de conseguirem enxergar a totalidade. Como nos ensinou

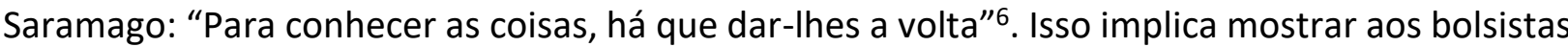
a complexidade da escola, como ela está atravessada por diferentes dimensões e como elas permeiam o fazer docente. Acredito que as bolsistas podem compreender essa complexidade porque estão mergulhadas no cotidiano da escola e porque a super-visão das professoras

\footnotetext{
${ }^{6}$ Depoimento de José Saramago no documentário “Janelas da alma”. Diretor: João Jardim e Walter Carvalho (2001). Periódico Horizontes - USF - Itatiba, SP-Brasil - e019003
} 
supervisoras Ihes permite fazer uma leitura ampliada da escola.

A afirmação acima guarda relação com as últimas considerações de Bétsamar, quando explicita que o lugar de professora supervisora do Pibid lhe permitiu "ampliar os horizontes dentro da escola".

Outro ponto que me vem à mente... A oportunidade de ser professor supervisor irá ampliar seus horizontes dentro da escola. Você passará a ter uma visão melhor do todo escolar, tendo mais facilidade para ir além de sua sala de aula e aprender sobre o funcionamento e organização da escola a partir do lugar da supervisão do Pibid. Lidar com trabalhos que se entrelaçam no ambiente escolar dará a você oportunidade de perceber um pouco dos desafios da gestão, dos desafios de lidar com diferentes e diferenças, de negociar, ceder, ser "política", em prol do alvo maior de uma escola - a aprendizagem de seus alunos. E, no nosso caso, também em prol do alvo maior do Pibid - a formação de futuros professores (Carta de Bétsamar, dezembro de 2016).

Ser professor supervisor amplia os horizontes na medida em que o subprojeto Pibid na escola requer as mediações das professoras supervisoras porque têm que estabelecer pontes na relação das professoras das salas de aula com os bolsistas; porque têm que articular o trabalho desenvolvido no subprojeto com professoras colaboradoras, gestão, funcionários; porque têm que lidar com a diversidade de concepções e práticas que sustentam o fazer docente na escola, na busca conjunta para que os alunos sejam beneficiados com as propostas do subprojeto Pibid, no nosso caso, com o trabalho com práticas de leitura e literatura.

Ampliar os horizontes implica também legitimar que ser professor supervisor é ser por cima de tudo "docente". Um docente que, ocasionalmente, ocupa o lugar de professor supervisor e que, por isso, é docente não apenas de sua turma, é docente de todos os alunos da escola, quando assume o compromisso de ser professor de futuros professores (bolsistas) que também trabalham diretamente com os alunos da escola. É um docente que se enxerga em constante constituição, ao perceber que pode aprender com as práticas dos seus colegas, também quando aprende com as oportunidades que a universidade lhe oferece, com a socialização de novos conhecimentos. Um docente que aprende, também, ao ser professor de futuros professores. Ser docente, ocupando o lugar de professor supervisor, possibilita reconhecer que se

Periódico Horizontes - USF - Itatiba, SP-Brasil - e019003 
ensina e se aprende constantemente, porém, é do lugar de professor supervisor que se consegue "ser um professor com capa de gestor", como considerado por Bétsamar:

[...] Enfim, não perca nunca de vista que antes e acima de tudo, você é docente, afinal, seu papel de professor supervisor só fará sentido atrelado a este fato. Sabendo-se docente, perceba, dia a dia, as contribuições do Pibid em seu constituir-se professor. Usufrua das possibilidades de formação continuada, tanto no seu momento de planejar/preparar as reuniões e atividades com os bolsistas, quanto nas oportunidades que a universidade lhe oferecerá. Percebase docente, estando neste lugar, não mais somente de seus alunos de cada ano letivo, mas também destes que estão em processo de constituir-se futuros docentes. Estando neste lugar, você terá chance de "ser" professor, vendo (e oportunizando) teoria e prática caminhando juntas, se complementando e não se excluindo. Você terá chance de "ser" professor de diversas classes (pense nas várias parcerias bolsistas-professores) e aprenda com as dinâmicas e diversidades de todas elas. Você terá chance de "ser professor" com "capa de gestor", afinal, como pontuado lá em cima, sua visão da escola e seus desafios se ampliarão (Carta de Bétsamar, dezembro de 2016).

Considero que a ideia de "ser professor com capa de gestor" explicita com clareza o trabalho desenvolvido pelas professoras supervisoras no contexto de nosso subprojeto. Não é possível compreender a organização do trabalho pedagógico da escola, apenas olhando para a dimensão técnica de nossa ação. Penso que o fazer das professoras supervisoras, trazido por Bétsamar, deixa em evidência que estar nesse lugar possibilita ampliar o horizonte dentro da escola, porque não era suficiente apenas lidar com as questões do planejamento no âmbito da sala de aula. Ocupar esse lugar diz de um compromisso com a formação integral dos futuros professores que ao estar vivendo o cotidiano escolar, conheceram as relações instituídas na escola, conheceram questões de legislação e políticas do próprio município e do país, conheceram aspectos relacionados com os direitos dos professores e suas atribuições, conheceram as contradições que se vivem no cotidiano escolar, conheceram a complexidade da escola e seus atravessamentos. Ocupar esse lugar diz de ampliar o horizonte e ter capa de gestor porque a implementação de um subprojeto Pibid na escola implica tecer pontes com todos os segmentos para colaborar com a aprendizagem de todos os alunos da escola, articular os

Periódico Horizontes - USF - Itatiba, SP-Brasil - e019003 
projetos de literatura desenvolvidos nas parcerias, envolver equipe de gestão da escola com questões próprias do Pibid, solicitando deles apoio para poder gerir o subprojeto.

Penso que o percurso formativo vivido pela professora supervisora legitima o que os autores citados anteriormente afirmaram nas suas pesquisas acerca das contribuições do Pibid na formação continuada do professor supervisor (FRANÇA, 2015; JARDILINO; OLIVIERI, 2013) e da legitimação do professor supervisor como colaborador e coformador (GASPAR, 2015, MATSUOKA, SIGNORELLI, ANDRÉ, 2013). Porém, faço um destaque para questões singulares que aparecem nas falas da professora supervisora Bétsamar e que dizem da ampliação do seu olhar para a totalidade da escola, da ideia de que o professor supervisor expande seus horizontes no contexto escolar, assumindo a "capa de gestor" ao articular, tecer, criar pontes entre os diferentes segmentos da escola para que o subprojeto possa se desenvolver, tendo como foco a aprendizagem de todos os alunos.

\section{Considerações finais}

O Pibid foi criado pensando na qualificação dos futuros docentes. Porém o programa tem atingido de forma positiva outros sujeitos que dele participam. Segundo André (2015), o impacto que o Pibid teve para os professores supervisores tem a ver com a possibilidade de se contatar novamente com o ambiente acadêmico, retomar estudos e, fundamentalmente, desenvolver trabalhos em parceria.

Gatti et al. (2014) consideram que os professores supervisores atuam "como coformadores no processo de iniciação à docência, em articulação com o formador da universidade" (p. 10). Assumir ser coformador implica desenvolver práticas formativas e mobilizar saberes de orientação para efetivamente colaborar na formação dos futuros professores. Talvez a potencialidade de "ser/estar professora supervisora" possa ser pensada para além da formação dos bolsistas, porque as ações desenvolvidas por aqueles que ocupam esse lugar irradiam para a escola como um todo; focam para a aprendizagem de todos os alunos; tecem pontes com os diferentes sujeitos da escola e, assim, colaboram tanto na construção da

Periódico Horizontes - USF - Itatiba, SP-Brasil - e019003 
escola como na melhor articulação escola-universidade.

Resgato as considerações de Chaluh et al. (2017) que, ao analisarem os processos desenvolvidos por professores supervisores junto aos bolsistas Pibid, indiciam alguns dos saberes profissionais que são exigidos para ser/estar professores supervisores: a ressignificação da própria experiência como docente e a articulação dos dois espaços formativos - escola e universidade e a colaboração entre os diferentes profissionais da escola o que guarda relação com a ideia de "ser docente com capa de gestor".

Saberes necessários às práticas que se constroem ao viver um Programa que está sustentado na colaboração de todos os que deles participam. Que valoriza, legitima e resgata os saberes produzidos pelos professores em exercício. Que compreende que para pensar a educação e a aprendizagem de todas as crianças se faz necessária uma aliança, um vínculo entre duas instituições que formam futuros professores. Na interlocução, na reflexão, na parceria é que se procura melhor pensar o fazer docente tendo como objetivo os alunos da Educação Básica.

\section{Referências}

ANDRÉ, M. Espaços alternativos de formação docente. In: GATTI, B. A. et. al. Por uma revolução no campo da formação de professores. São Paulo: Editora Unesp, 2015, p.97-115.

ANDRÉ, M. Políticas e programas de apoio aos professores iniciantes no Brasil. Caderno de Pesquisa. v.42, n.145, p.112-129, jan./abr. 2012. DOI: http://dx.doi.org/10.1590/S010015742012000100008. Disponível em: http://www.scielo.br/pdf/cp/v42n145/08.pdf. Acesso em: 9 out. 2014.

CHALUH, L. N., et al. Saberes dos supervisores no contexto do Pibid: formação e parceria. Comunicações, Piracicaba, v.24, n.1, p.125-147, jan./abr. 2017.

DEMOS, T. V.; TERRAZZAN, E. A. A valorização profissional do bolsista supervisor nas normativas legais do PIBID/CAPES. In: Congresso Nacional de Educação, 2013, Curitiba. Anais... Curitiba: PUCPR, 2015. Disponível em:

https://educere.pucpr.br/p1/anais.html?tipo=2\&titulo=A+valoriza\%C3\%A7\%C3\%A3o+profissio nal+do+bolsista+supervisor+nas+normativas+legais+do+PIBID\%2FCAPES\&edicao=5\&autor=\&ar ea=. Acesso em: 27 mar. 2016.

Periódico Horizontes - USF - Itatiba, SP-Brasil - e019003 
ESCOLA DANTE EgRÉGgIO. Projeto Político Pedagógico. Rio Claro, 2011.

FRANÇA, M. do S. L. M. Caminhos da formação permanente: o caso dos professores supervisores do PIBID. In: Congresso Nacional de Educação, 2013, Curitiba. Anais... Curitiba: PUCPR, 2015. Disponível em: https://educere.pucpr.br/p1/anais.html?tipo=\&titulo=Caminhos+da+forma\%C3\%A7\%C3\%A3o+ permanente\%3A+o+caso+dos+professores+supervisores+do+Pibid\&edicao=5\&autor=Maria+do +Socorro+Lima+Marques+Fran\%C3\%A7a\&area=. Acesso em: 27 mar. 2016.

FREITAS, M. T. A perspectiva sócio-histórica: uma visão humana da construção do conhecimento. In: FREITAS, M. T.; JOBIM e SOUZA, S.; KRAMER, S. (Orgs.). Ciências humanas e pesquisa: leitura de Mikhail Bakhtin. 1.ed. São Paulo: Cortez, 2003. p. 26-38. (Coleção questões da nossa época; v. 107).

GASPAR, M. de L. R. A participação dos professores da educação básica no PIBID: reflexões sobre a prática da supervisão. In: Congresso Nacional de Educação, 2015, Curitiba. Anais... Curitiba: PUCPR, 2015. Disponível em:

https://educere.pucpr.br/p1/anais.html?tipo=2\&titulo=A+participa\%C3\%A7\%C3\%A3o+dos+pro fessores+da+educa\%C3\%A7\%C3\%A3o+b\%C3\%A1sica+no+PIBID\%3A+reflex\%C3\%B5es+sobre+a +pr\%C3\%A1tica+da+supervis\%C3\%A3o\&edicao=5\&autor=\&area=. Acesso em: 27 mar. 2016.

GATTI, B. A. et al. Um estudo avaliativo do Programa Institucional de Bolsa de Iniciação à Docência (Pibid). 1. ed. São Paulo: FCC/SEP, 2014.

GINZBURG, C. Sinais. Raízes de um paradigma indiciário. In: GINZBURG, C. Mitos, emblemas, sinais. São Paulo: Companhia das Letras, 1989. p 143-179.

JARDILINO, J. R. L.; OLIVERI, A. M. R. A formação continuada de professores no âmbito do PIBID na região dos Inconfidentes - MG. In: Congresso Nacional de Educação, 2013, Curitiba. Anais... Curitiba: PUCPR, 2013. Disponível em:

https://educere.pucpr.br/p1/anais.html?tipo=2\&titulo=\&edicao=4\&autor=JARDILINO\&area=. Acesso em: 27 mar. 2016.

MATSUOKA, S.; SIGNORELLI, G.; ANDRÉ, M. E. D. A integração universidade-escola pela atuação de uma supervisora do PIBID. In: Congresso Nacional de Educação, 2013, Curitiba. Anais... Curitiba: PUCPR, 2013. Disponível em: http://educere.bruc.com.br/arquivo/pdf2013/10173_5703.pdf. Acesso em: 27 mar. 2016.

Recebido em maio de 2018.

Aprovado em outubro de 2018.

Periódico Horizontes - USF - Itatiba, SP-Brasil - e019003 